\title{
Arsenic Removal using Silver-Impregnated Prosopis spicigera L. wood (PSLW) Activated Carbon: Batch and Column Studies
}

\section{*11MURUGAN, M; ${ }^{2}$ JANSIRANI, M; ${ }^{3}$ SUBRAMANIAM, P; ${ }^{4}$ SUBRAMANIAN, E}

\author{
${ }^{I}$ Associate Professor, Department of Chemistry, Sri K. G. S. Arts College, Srivaikuntam, Tuticorin, 628 619, Tamil Nadu, India; \\ ${ }^{2}$ Assistant Professor, Department of Chemistry, Govindammal Aditanar College for Women, Tiruchendur, Tuticorin, 628 215, Tamil Nadu, \\ India; \\ ${ }^{3}$ Principal, Aditanar College of Arts and Science, Tiruchendur, Tuticorin, 628 216; \\ ${ }^{4}$ Professor, Department of Chemistry, Manonmaniam Sundaranar University, Tirunelveli 627 012, Tamil Nadu, India \\ Email: jansirani.m2011@gmail.com
}

\begin{abstract}
Silver-impregnated carbon (SIC) and its precursor (un-impregnated) derived from an easily available low cost plant material Prosopis spicigera L. wood (PSLW) carbon was investigated for their ability to remove arsenic from aqueous solutions in batch and column experiments. Arsenic uptake has no regular trend with increasing $\mathrm{pH}$; contains two adsorption maxima, the first adsorption maximum at $\mathrm{pH} 4.0$ and a second adsorption maximum at $\mathrm{pH} 10.0$. The extent of As (III) removal increased with increase in temperature. As (III) sorption kinetics was well fitted by pseudo second order with pore diffusion as rate determining step. The applicability of Langmuir isotherm suggests the formation of monolayer coverage of As (III) at the outer surface of the adsorbent. Thermodynamic parameters show that the adsorption was spontaneous and endothermic in nature. Column experiments were done using Thomas model, the maximum adsorption capacity of SIC was found to be $9.36 \mathrm{mg} / \mathrm{g}$.
\end{abstract}

DOI: https://dx.doi.org/10.4314/jasem.v21i7.15

Copyright @ 2017 Murugan et al. this is an open access article distributed under the Creative Commons Attribution NonCommercial License (CC-BY-NC), which permits unrestricted use, distribution, and reproduction in any medium, provided the original work is properly cited.

Received 10 September 2017, received in revised form 15 October 2017, accepted 02 December 2017.

Keywords: Adsorption, Arsenic, batch adsorption, langmuir isotherm, silver-impregnated carbon (SIC), Thomas model.

Ground water is the prime source of drinking water and meets the needs of households' worldwide. Arsenic is known to be one of the naturally occurring element in ground water whichis associated with adverse health effects. Arsenic concentration in water varies from less than 0.05 to more than $5000 \mu \mathrm{g} / \mathrm{L}$ depending on the source of arsenicand the arsenic concentration in drinking water is of great human health concern in some regions of Bangladesh, India, Nepal, Mexico and Argentina (Wagle and Shipley, 2016). Recent literature reveals that As(III) and As $(\mathrm{V})$ oxyanions with varying concentration have been distributed regionally across the United States (USA) (Sorg et al., 2014). The potable water is considered to be safe for human consumption if the concentration of arsenic in water is $10 \mu \mathrm{g} / \mathrm{L}$. Therefore it is essential to remove arsenic from potable water resources.

The important process listed for the removal of arsenic are oxidation-reduction, precipitation, coprecipitation, adsorption, electrolysis and cementation, solvent extraction, ion exchange, ion floatation, coagulation and biological processing (Zhao et al., 2012; Bilici Baskan and Pala, 2010; Sen et al., 2010; Shobana et al., 2014; Pio et al., 2015;
Sneh Lata and Samadder, 2016; Overah and Odiachi, 2017). Among the techniques, adsorption by activated carbon is accepted to be the best available technology for the removal of pollutants. The main disadvantage of activated carbon adsorption technology is its high cost. This can be overcome by preparing activated carbon from renewable biomass in natureand tailoring the carbon surface to enhance the removal capacity (Hoskins et al., 2002).

In our previous work (Jansi Rani et al., 2014) activated carbon prepared from a low cost biomass Prosopis spicigera L. wood (PSLW) carbon was used to remove arsenic from aqueous solution. In the present work, the PSLW carbon impregnated with silver known as silver-impregnated carbon (SIC) was employed to remove arsenic from aqueous solution. The physical and chemical characterization of SIC by scanning electron micrographs (SEM), Fourier transform infra-red spectroscopy (FT-IR), Energydispersive X-ray (EDX) and Boehm estimation were conducted and further the potential of the SIC was evaluated for As(III) removal. The study was to examine As(III) adsorption capacity of SIC by batch studies and to investigate the As(III) uptake characteristics of SIC by column studies. 


\section{MATERIALS AND METHODS}

Preparation of PSLW activated carbon and silver impregnation: PSLW plant material used in the present work was collected from the dry land area of Tiruchendur in Thoothukudi district, Tamil Nadu state, India. Activated carbon was prepared from the collected plant material as follows. The branches and roots of the tree were cut into pieces and piled up on a firing hearth. Before firing, the heaped wood pieces were enclosed by fresh plantain pith and the whole mass was covered and plastered with layers of wet clay. This arrangement prevented the direct-entry of air into wood pieces and hence prohibited burning of wood and becoming ash. After $48 \mathrm{~h}$ of continuous firing and subsequent natural cooling, the activated carbon was obtained. After removing noncarbonaceous materials like plantain pith, clay-mud etc., carbon was isolated, crushed into fine powder and sieved to 75 micron particles. Silver impregnation was carried out using the following simple procedure. $5 \mathrm{~g}$ of carbon was suspended in $100 \mathrm{ml}$ of $0.1 \mathrm{~N} \mathrm{AgNO}_{3}$ solution. To this $100 \mathrm{ml}$ of $0.2 \mathrm{~N}$ glucose solution was added and mixed thoroughly, heated for an hour in water bath and then cooled to room temperature. Silver-impregnated carbon (SIC) was filtered and washed with distilled water to remove the excess of glucose. It was dried and sieved to 75 micron particle and stored in air tight bottle and used for adsorption study.

Adsorbent characterization: Surface areas of PSLW carbon and the SIC was estimated using methylene blue dye adsorption method on a per gram basis at 30 ${ }^{0} \mathrm{C}$ as described in literature. A SEM (Hitachi S 450 Japan) was used to study the surface characteristics of the sorbent materials before and after adsorption of arsenic. Elemental mapping of the adsorbents' surfaces were conducted with Energy-dispersive Xray (EDX) (Thermo NORAN system Vantage).

Potentiometric titration with acid/alkali was used to determine the $\mathrm{pH}_{\mathrm{zpc}}$ (zero point charge) of the adsorbents. Selective neutralization of acidic/basic surface groups by varying strength of acid/base were determined by Boehm method. This method was used to determine the surface functional groups such as carboxyl, lactone and phenolic groups etc. Fourier Transform Infra-Red (FT-IR) spectroscopic study of adsorbents was performed with Jasco FT-IR 410 spectrophotometer to find the nature of the functional groups. As(III) ion in aqueous solution was estimated using Atomic Absorption Spectrophotometer (Shimadzu, AA-6300). A portable digital $\mathrm{pH}$ meter with glass electrode (model LT-120 ELICO) was utilized for the measurement of $\mathrm{pH}$ values.
Batch adsorption studies: The arsenic stock solution $\left(1000 \mathrm{mg} / \mathrm{L} \quad \mathrm{As}_{2} \mathrm{O}_{3}\right)$ was diluted to desired concentration of experimental As(III) solution. An adsorbent dose of $2 \mathrm{~g} / \mathrm{L}$ was kept constant for all the batch experiments. The initial $\mathrm{pH}$ of $\mathrm{As}(\mathrm{III})$ solution was adjusted using $0.1 \mathrm{~mol} / \mathrm{L} \mathrm{NaOH}$ and $0.1 \mathrm{~mol} / \mathrm{L}$ $\mathrm{HCl}$ solutions. Batch adsorption equilibrium experiments were performed using $0.1 \mathrm{~g}$ of SIC (particle size 75 micron) in $50 \mathrm{~mL}$ of As(III) solution and agitated in a thermostatic shaker. After adsorption, the adsorbent was separated by filtration and the concentration of $\mathrm{As}(\mathrm{III})$ in the filtrate was investigated using Atomic Absorption Spectrophotometer (Shimadzu, AA-6300). The batch experiments were performed to study the effect of various parameters such as $\mathrm{pH}(1-10)$, contact time (5-120 min) and temperature $\left(30-45^{\circ} \mathrm{C}\right)$. The amount of As(III) adsorbed per unit mass of the adsorbent (q) was calculated using equation (1),

$$
\mathrm{q}=\left[\left(\mathrm{C}_{\mathrm{i}}-\mathrm{C}_{\mathrm{f}}\right) \mathrm{V}\right] / \mathrm{W}
$$

where, $\mathrm{C}_{\mathrm{i}}$ and $\mathrm{C}_{\mathrm{f}}$ are the initial and free concentrations of $\mathrm{As}(\mathrm{III})$ in $\mathrm{mg} / \mathrm{L}$ respectively; $\mathrm{V}$ is the volume of As(III) solution in $\mathrm{mL}$ and $\mathrm{W}$ is the weight of the adsorbent in $\mathrm{g}$.

Column study: In column study, $5 \mathrm{~g}$ of SIC (particle size 75 micron) was washed with distilled water to remove carbon fines and then packed evenly in a glass column ( $1.5 \mathrm{~cm}$ diameter) by tapping to reduce air voids in the carbon bed for a bed height of $7.1 \mathrm{~cm}$. As(III) solution $(500 \mathrm{mg} / \mathrm{L})$ was drawn into the column at a rate of $0.5 \mathrm{~mL} / \mathrm{min}$ from a separating funnel. Effluents were collected at regular intervals of time and analyzed. The column flow was terminated when the As(III) concentration ratio of the effluent to influent reached a value of 0.8 .

\section{RESULTS AND DISCUSSIONS}

Adsorbent characterization of SIC

Energy-dispersive X-ray (EDX) analysis shows the percent of impregnation of silver is 9.77 weight \% of carbon. Surface area of SIC is slightly higher than the PSLW carbon indicating the segregation of carbon particle after silver impregnation. There are evidences from the SEM study that the carbon surface is segregated and smoothened in the SIC. SEM analysis (Figure 1) shows that the impregnation of silver as white patches on the surface of carbon. The observe decrease in the basic sites and cation exchange capacity may be due to adsorption of $\mathrm{Ag}^{+}$ ion onto the basic sites. Further, it is shown that there is a significant increase in lactone and the amount of phenolic groups after impregnation which shows the oxidation of carbon surface. The $\mathrm{pH}_{\mathrm{zpc}}$ values of 
PSLW carbon and SIC are found as 6.98 and 7.06 respectively.
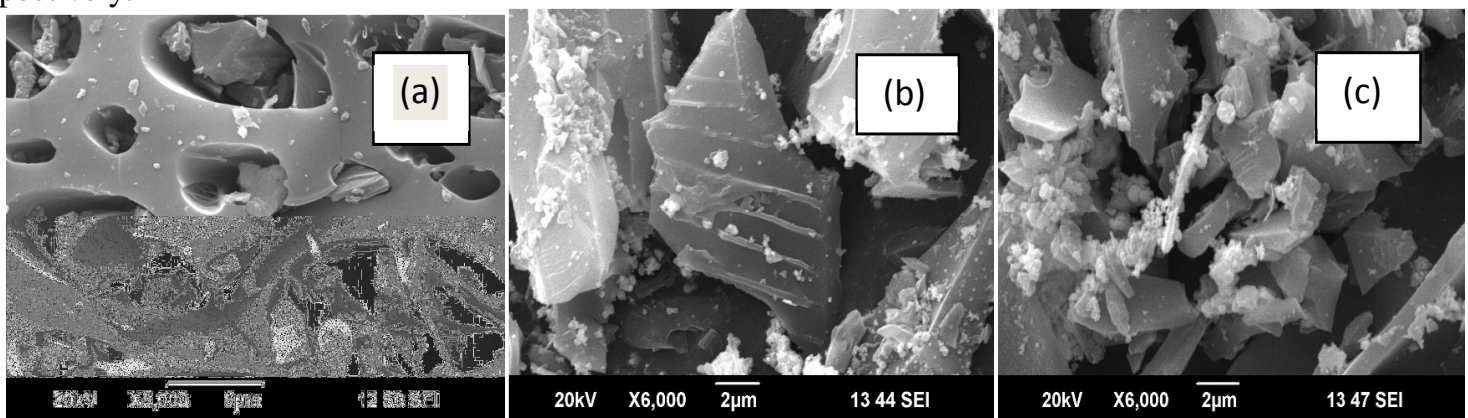

Fig. 1: SEM images of (a) PSLW carbon (b) SIC and (c) As(III)-loaded SIC (x 6000 magnification).

The slightly higher $\mathrm{pH}_{\mathrm{zpc}}$ value of SIC shows the presence of more acidic sites on SIC than PSLW carbon. Thus the SIC differ significantly from PSLW carbon in physical and chemical characteristics due to silver impregnation.

Effect of $p H$ : The experiments were carried out to investigated the effect of $\mathrm{pH}$ on the adsorption of As(III) onto SIC. Arsenic adsorption onto any adsorbent depends on the arsenic valence as well as $\mathrm{pH}$ of the solution. Figure 2 depicts the effect of $\mathrm{pH}$ over a range of 1-10.0. Though no regular trend in adsorption is seen with $\mathrm{pH}$, the figure shows two maxima, one at $\mathrm{pH} 4.0$ and another at about $\mathrm{pH}$ 10.0. For an initial As(III) concentration of $1000 \mathrm{mg} / \mathrm{L}$ the maximum adsorption capacity of $\mathrm{As}(\mathrm{III})$ at $\mathrm{pH} 4.0$ is $98.2 \mathrm{mg} / \mathrm{g}$ and at $\mathrm{pH} 10.0$ it is found to be 207.5 $\mathrm{mg} / \mathrm{g}$. It was postulated that under acidic condition the metallic silver get oxidized in aqueous solution according to the following reaction (Hoskins et al., 2002).

$\mathrm{O}_{2}(\mathrm{aq})+4 \mathrm{H}^{+}(\mathrm{aq})+\mathrm{Ag}^{\mathrm{O}}(\mathrm{s}) \longrightarrow 4 \mathrm{Ag}^{+}(\mathrm{aq})+$ $2 \mathrm{H}_{2} \mathrm{O}(\mathrm{l}) \quad \Delta \mathrm{G}^{\mathrm{o}}=-182.2 \mathrm{~kJ} / \mathrm{mole}$.

From the SEM and EDX analyses it is evident that the silver on the surface of SIC exists as metallic silver (i.e. $\mathrm{Ag}^{\mathrm{o}}$ ). Therefore it is assumed that at $\mathrm{pH}$ 4.0, $\mathrm{Ag}$ is oxidized to $\mathrm{Ag}^{+}$ion which reacts with $\mathrm{AsO}_{3}{ }^{-}$to give $\mathrm{Ag}_{3} \mathrm{AsO}_{3}$ precipitate and gets adsorbed on the surface of SIC. As the $\mathrm{pH}$ rises the formation of $\mathrm{Ag}^{+}$is limited and at alkaline $\mathrm{pHs}$ silver exists as $\mathrm{AgOH}$ and the following reaction may occur.

$$
\begin{aligned}
\mathrm{C}-\mathrm{AgOH}+\mathrm{H}_{2} \mathrm{AsO}_{3}{ }^{-} & \longrightarrow \mathrm{C}-\mathrm{AgH}_{2} \mathrm{AsO}_{3} \\
2 \mathrm{C}-\mathrm{AgOH}+\mathrm{HAsO}_{3}{ }^{2-} \longrightarrow\left(\mathrm{C}-\mathrm{Ag}_{2} \mathrm{HAsO}_{3}\right. & \longrightarrow
\end{aligned}
$$

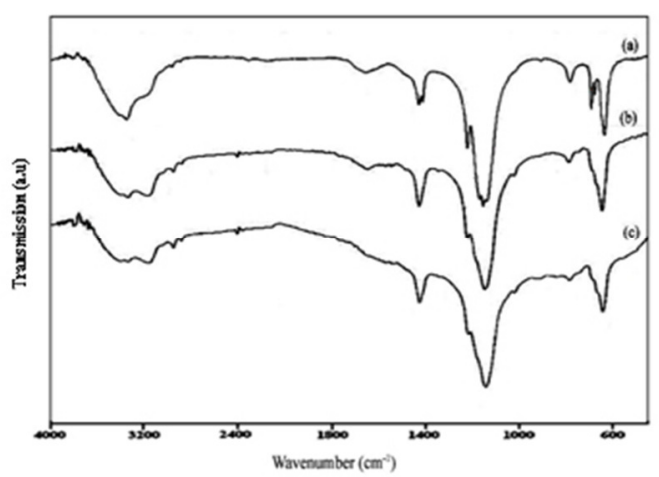

Fig. 2: Adsorption of As(III) on SIC as a function of pH. Fig. 3: FT-IR spectra of (a) PSLW carbon (b) SIC and (c) As(III)-loaded SIC.

Further at alkaline $\mathrm{pHs}$, the $\mathrm{Na}^{+}$ions may also bind to the negatively charged surface of SIC and neutralize the charges partially (Mehta and Chaudhari, 2015). Therefore in the alkaline $\mathrm{pH}$ the $\mathrm{H}_{2} \mathrm{AsO}_{3}{ }^{-}$and $\mathrm{HAsO}_{3}{ }^{2-}$ species may also be bound to the surface of SIC carbon by vander Waals forces in addition to the above process. Further the FT-IR study shows the surface of SIC consists of lactone and phenolics groups (Figure 3). These surface groups may form complex with As(III) which is evident from the IR spectroscopy. The in plane bending of $-\mathrm{OH}$ group occurs at $2273 \mathrm{~cm}^{-1}$ is blue shifted and C-O stretching at $1160 \mathrm{~cm}^{-1}$ in SIC disappeared at As(III) loadedSIC. 
Effect of contact time and temperature: Contact time is a significant yardstick in determining the rate and equilibrium time of adsorption process.

Table 1: Langmuir constants at different temperatures

\begin{tabular}{clll}
\hline $\begin{array}{c}\text { Temp } \\
(\mathrm{C})\end{array}$ & $\begin{array}{c}\mathrm{Q}_{\mathrm{o}} \\
(\mathrm{mg} / \mathrm{g})\end{array}$ & $\begin{array}{l}\mathrm{b}\left(10^{3}\right) \\
(\mathrm{L} / \mathrm{mg})\end{array}$ & $\mathrm{R}_{\mathrm{L}}$ \\
\hline 30 & 32.39 & 1.90 & 0.3448 \\
35 & 34.72 & 1.93 & 0.3415 \\
40 & 44.64 & 2.15 & 0.3174 \\
45 & 59.17 & 2.40 & 0.2920 \\
\hline
\end{tabular}

The characteristics of SIC and its available adsorption sites affect the course of time to reach the equilibrium. As(III) removal increases with increasing contact time; an initial rapid uptake of As(III) followed by a gradual/slowed uptake at later stage. The removal rate gradually slows down and equilibrium reaches at $120 \mathrm{~min}$. After reaching the state of equilibrium, there is no remarkable increase in the adsorption capacity. The maximum adsorption capacity of As(III) was found to be $196.43 \mathrm{mg} / \mathrm{g}$ for an initial concentration of $1000 \mathrm{mg} / \mathrm{L}$. Temperature plays a key role in determining the adsorption capacity and in this study temperature was varied from 30 to $45{ }^{\circ} \mathrm{C}$. It shows the variation of adsorption capacity with temperature, which increases with increase in temperature. Thus, increase in adsorption capacity with temperature clearly demonstrates that the adsorption of As(III) on SIC is an endothermic process.

Isotherm analysis: The adsorption data were analyzed with two well-known adsorption isotherm models namely Langmuir and Freundlich models.

Table 2: Comparison of pseudo-first order and pseudo-second order model parameters

\begin{tabular}{lcccccccc}
\hline \multicolumn{4}{c}{ Pseudo-first order model } & \multicolumn{5}{c}{ Pseudo-second order model } \\
\hline $\begin{array}{c}\mathrm{As}(\mathrm{III}) \\
(\mathrm{mg} / \mathrm{L})\end{array}$ & $\mathrm{T}^{\circ} \mathrm{C}$ & $\begin{array}{c}\mathrm{q}_{\mathrm{e}}(\mathrm{exp}) \\
(\mathrm{mg} / \mathrm{g})\end{array}$ & $\begin{array}{c}\mathrm{k}_{1} \\
\left(\mathrm{~min}^{-1}\right)\end{array}$ & $\begin{array}{c}\mathrm{qe}_{\mathrm{e}}(\mathrm{cal}) \\
(\mathrm{mg} / \mathrm{g})\end{array}$ & $\mathrm{R}^{2}$ & $\begin{array}{c}\mathrm{k}_{2} \times 10^{2} \\
(\mathrm{~g} / \mathrm{mg} / \mathrm{min})\end{array}$ & $\begin{array}{c}\mathrm{q}_{\mathrm{e}}(\mathrm{cal}) \\
(\mathrm{mg} / \mathrm{g})\end{array}$ & $\mathrm{R}^{2}$ \\
& & & & & & & & \\
1000 & 30 & 196.43 & 0.0279 & 140.799 & 0.9805 & 2.82 & 219.05 & 0.993 \\
& 35 & 199.15 & 0.0338 & 131.009 & 0.9976 & 4.12 & 218.82 & 0.997 \\
& 40 & 224.10 & 0.0334 & 139.740 & 0.9866 & 4.45 & 242.72 & 0.998 \\
& 45 & 235.05 & 0.0453 & 140.472 & 0.9957 & 5.58 & 250.16 & 0.999 \\
\hline
\end{tabular}

The experimental data did not fit well with the Freundlich model but linear correlation is obtained with Langmuir model. This is evident from the linear plots of $\mathrm{C}_{\mathrm{f}} / \mathrm{q}$ against $\mathrm{C}_{\mathrm{f}}$ for the adsorption of $\mathrm{As}(\mathrm{III})$ on SIC (Figure 4).

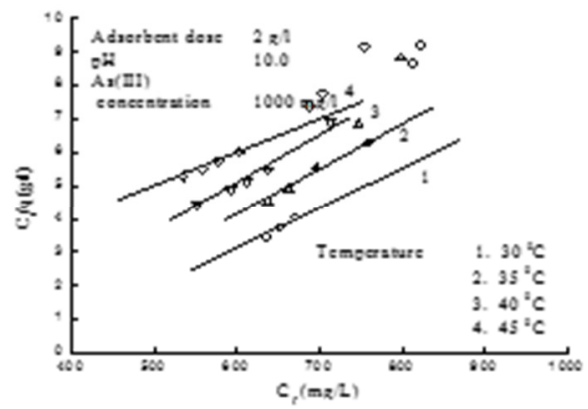

Fig. 4: Langmuir plot at different temperatures.

The $\mathrm{Q}_{\mathrm{o}}$ and $\mathrm{b}$ can be determined from the slope and the intercept of the linear plots and are given in Table 1. All these facts prove that As(III) is adsorbed in a monolayer on the surface of the adsorbent. The Langmuir constant, $b$, is used to assess the affinity between the adsorbate and adsorbent which steadily increases with temperature. Further dimensionless separation factor $\left(R_{L}\right)$ is calculated. It is observed that the $R_{L}$ values (Table 1) lie between 0 and 1 , which establishes the truth that the adsorption isotherm is favorable under the studied conditions.

Adsorption kinetics: The kinetics of As(III) adsorption on SIC was examined with pseudo-first order and pseudo-second order kinetic models which are expressed in equations (2) and(3),

$$
\begin{gathered}
\log \left(\mathrm{q}_{\mathrm{e}}-\mathrm{q}\right)=\log \mathrm{q}_{\mathrm{e}}-\left(\mathrm{k}_{1} \mathrm{t} / 2.303\right) \\
\mathrm{t} / \mathrm{q}_{\mathrm{t}}=1 / \mathrm{k}_{2} \mathrm{q}_{\mathrm{e}}^{2}+\mathrm{t} / \mathrm{q}_{\mathrm{e}}
\end{gathered}
$$

where, $\mathrm{q}_{\mathrm{e}}$ and $\mathrm{q}_{\mathrm{t}}$ are the amount of As(III) adsorbed $(\mathrm{mg} / \mathrm{g})$ at equilibrium and at time ' $\mathrm{t}$ ' ( $\mathrm{min}$ ), respectively. $\mathrm{k}_{1}(\mathrm{~L} / \mathrm{min})$ and $\mathrm{k}_{2}(\mathrm{~g} / \mathrm{mg} \mathrm{min})$ are the adsorption rate constants of first order and second order adsorption.

In addition, the initial adsorption rate, $\mathrm{h}(\mathrm{mg} / \mathrm{g} / \mathrm{min})$ equal to $\mathrm{k}_{1} \mathrm{q}_{\mathrm{e}}$ or $\mathrm{k}_{2} \mathrm{q}_{\mathrm{e}}{ }^{2}$ was also calculated. For the studied initial concentrations and temperatures, the rate constants $\left(\mathrm{k}_{1}\right.$ and $\left.\mathrm{k}_{2}\right)$, theoretical equilibrium adsorption capacities, $\mathrm{q}_{\mathrm{e}}$ (cal) calculated from the slope and intercept of the linear plots of the pseudo- 
first order and pseudo-second order kinetic model and the co-efficient of linear correlation $\left(\mathrm{R}^{2}\right)$ at different temperatures are given in Table 2. An analysis of the values in Table 2, particularly the agreement between $\mathrm{q}_{\mathrm{e}}(\exp )$ and $\mathrm{q}_{\mathrm{e}}(\mathrm{cal})$ and the value of $\mathrm{R}^{2}$ towards unity between pseudo first-order and pseudo-second order models clearly reveals that pseudo-second order model fits better to the data than the pseudo-first order model. Therefore it is inferable that the adsorption of As(III) on SIC is a second order type process.

Thermodynamic behavior: The thermodynamic constants, standard free energy change $\left(\Delta G^{0}\right)$, standard enthalpy change $\left(\Delta \mathrm{H}^{\mathrm{o}}\right)$ and standard entropy change $\left(\Delta S^{\circ}\right)$ were determined to know the thermodynamic feasibility of the adsorption process. The negative values of $\Delta G^{0}$ indicate the spontaneous nature of adsorption process. The increase in adsorption capacity with increase in temperature from $30{ }^{0} \mathrm{C}$ to $45{ }^{0} \mathrm{C}$ demonstrates the endothermic nature. Therefore $\Delta \mathrm{H}^{\mathrm{o}}$ needs to be positive for a spontaneous process and the same has been observed true $(0.472 \mathrm{~kJ} / \mathrm{mol})$. The positive value of $\Delta \mathrm{S}^{\mathrm{o}}$ (16.65) shows the affinity of the adsorbent towards As(III) species and suggests the possibility of some structural changes in the solvent cluster around the As(III)-SIC complex.

Intra-particle diffusion: To determine whether the intra-particle diffusion is the rate determining step or not, the data were analysed using Finkiam diffusion law. The intra-particle diffusion constant, $\mathrm{k}_{\mathrm{i}}$ value is calculated from the slope of the plot of $\mathrm{q}_{\mathrm{t}} \mathrm{vs} \mathrm{t}^{1 / 2}$. The plots do not pass through the origin, which indicate that the above diffusion law is applicable. The pore diffusion constants are 12.4076, 12.8549, 17.7870 and $23.0400(\mathrm{mg} / \mathrm{g} / \mathrm{min})$ at different temperatures. The increase in $\mathrm{k}_{\mathrm{i}}$ values with increase in temperature, clearly demonstrates that the intraparticle diffusion becomes easier at higher temperature. The plot also indicated that intra-particle diffusion is not the only rate-controlling step because it did not pass through the origin. The linearity of the plots demonstrated that intra-particle diffusion plays a significant role in the uptake of the adsorbate by adsorbent.

Column study: Column adsorption process is vital to industrial process for waste water treatment. The observed data fit to the linearised form of the Thomas model (Thomas, 1948) and are given in equation (4),

$$
\log \left(\mathrm{C}_{\mathrm{o}} / \mathrm{C}_{\mathrm{e}}-1\right)=\mathrm{kq}_{\mathrm{o}} \mathrm{M} / \mathrm{Q}-\mathrm{kC}_{\mathrm{o}} \mathrm{V} / \mathrm{Q}
$$

where, $\mathrm{C}_{\mathrm{o}}$ and $\mathrm{C}_{\mathrm{e}}$ are the influent and effluent $\mathrm{As}(\mathrm{III})$ concentrations $(\mathrm{mg} / \mathrm{L})$ respectively. $\mathrm{k}$ stands for the Thomas rate constant $(\mathrm{mL} / \mathrm{min} / \mathrm{mg}) ; \mathrm{q}_{\mathrm{o}}$ is the maximum solid phase concentration of solute $(\mathrm{mg} / \mathrm{g})$; $\mathrm{M}$ is the mass of the adsorbent $(\mathrm{g})$; and $\mathrm{V}$ is the throughput volume $(\mathrm{mL} / \mathrm{min})$. For an initial concentration of As(III) $500 \mathrm{mg} / \mathrm{L}$, the concentrations of As(III) in effluent was found to be zero for the first 65 bed volumes, approximately $85 \%$ of As(III) was retained for 5 bed volumes, $68 \%$ for another 10 bed volumes and as evident from the curve, the retention of As(III) by the column gradually declines as the bed volume increases. The values of $\mathrm{k}$ and $\mathrm{q}_{\mathrm{o}}$ are computed from the slope and intercept of the linear plot of $\log \left(\mathrm{C}_{\mathrm{o}} / \mathrm{C}_{\mathrm{e}}-1\right)$ versus $\mathrm{V}$ and they are found as $5.311 \times 10^{-2} \mathrm{~mL} / \mathrm{min} / \mathrm{mg}$ and $9.36 \mathrm{mg} / \mathrm{g}$. Thus from column analysis it has been shown that can be used in industrial processes for the removal of As(III) from aqueous systems.

Desorption study: Desorption was carried out by placing $0.1 \mathrm{~g}$ of As(III) loaded SIC in $50 \mathrm{ml}$ of $0.1 \mathrm{~N}$ $\mathrm{HCl}$ at $30{ }^{\circ} \mathrm{C}$. The percent desorption was 86.4. During the experiment, leaching of $\mathrm{Ag}$ was not observed because the solution tested with potassium chromate did not give any characteristic colouration.

Conclusions: In this study, silver impregnated carbon (SIC) was prepared from PSLW carbon and its adsorption capacity was investigated using batch and column study. Silver content of carbon and $\mathrm{pH}$ play vital role in the adsorption process. Metallic silver impregnated on SIC is oxidized under acidic conditions. The adsorption at $\mathrm{pH} 4.0$ is due to coulombic interaction between $\mathrm{As}$ (III) and $\mathrm{Ag}^{+}$ion while at higher $\mathrm{pH} 10.0$ the sorption is due to vander Waals interaction and complex formation of $\mathrm{As}$ (III) with surface functional groups. It was found that desorption of As(III) is possible with $0.1 \mathrm{~N} \mathrm{HCl}$. This work provides way for developing other silver impregnating adsorbents for As(III) removal.

\section{REFERENCES}

Bilici Baskan, M; Pala, AA (2010). Statistical experiment design approach for Arsenic removal by Coagulation process using Aluminum Sulfate.Desalination, 254: 42-48.

Hoskins, JS; Karanfil, T; Serki, SM (2002). Removal of sequestration of Iodide usingSilver impregnated activated carbon. Environ. Sci. Technol.36: 784-789.

Jansi Rani, M; Murugan, M; Subramaniam, P; Subramanian, E (2014). Adsorptive removal of arsenic from aqueous solution on PSLW carbon (Prosopis spicigera L. wood): Equilibrium, kinetics, thermodynamics and 
home water treatment studies. Res. J. Chem. Environ. 18: 16-24.

Mehta, VS; Chaudhari, SK (2015). Arsenic removal from simulated groundwater using household filter columns containing iron filings and sand. J. Water Proc. Eng.6:151157.

Overah, LC; Odiachi, I (2017). Evaluation of Dacryodes edulis (native peear) seed biomass for $\mathrm{Pb}(\mathrm{II})$ sorption from aqueous solution. J. Appl. Sci. Environ. Manag. 21(1): 186-199.

Pio, I; Scarlino, A; Bloise, E; Mele, G; Santoro, O; Pastore, T; Santoro, T (2015). Efficient removal of low-arsenic concentrations from drinking water by combined coagulation and adsorption processes. Sep. Purifi. Technol. 147: 284-291.

Schwarz, JA; Driscoll, C; Bhanot, AK (1984). The zero point charge of silica-alumina oxide suspensions. J. Colloid Interface Sci. 97: 5561.

Sen, M; Manna, A; Pal, P (2010). Removal of Arsenic from contaminated ground water by Membrane-integrated hybrid treatment system. J. Memb. Sci. 354: 108-113.
Shobana, R; Arockia Sahayaraj, P; Dharmalingam, V; Soruba, R (2014). Adsorption study on Zinc (II) ions from aqueous solution using chemically activated fruit of Kigelia Pinnata (JACQ) DC carbon. Inter. Res. J. Environ. Sci. 3(9): 65-69.

Sneh Lata, SR; Samadder (2016) Removal of arsenic from water using nano adsorbents and challenges: A review. J. Environ. Manage. 166 (15): 387-406.

Sorg, TJ; Chen, ASC; Wang, L (2014) Arsenic species in drinking water wells in the USA with high Arsenic concentrations. Water Res.48: 156-169.

Thomas H. C. (1948). Chromatography: A Problem in Kinetics. Annuals of New York Academy Sciences, 49: 161-182.

Wagle, D; Shipley, HJ (2016). Adsorption of Arsenic (V) to Titanium dioxide nanoparticles: Effect of particle size, solid concentration, and other metals. Environ. Eng. Sci. 33(5): 299-305.

Zhao, C; Du, S; Wang, T; Zhang, J; Luan, Z (2012).Arsenic Removal from Drinking Water by Self-Made PMIA Nanofiltration Membrane.Adv. Chem. Eng. Sci. 2(3): 366371. 